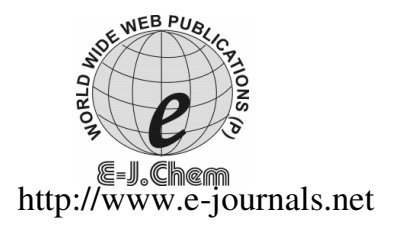

ISSN: 0973-4945; CODEN ECJHAO

E-Journal of Chemistry

2011, 8(4), 1620-1625

\title{
Simultaneous HPLC Determination of Methocarbamol, Paracetamol and Diclofenac Sodium
}

\author{
DESHMUKH HAFSA, S. CHANDA and PRADNYA J. PRABHU* \\ Department of Chemistry \\ K. J. Somaiya College of Science and Commerce \\ Vidyavihar (E), Mumbai-400077, India \\ pjprabhu@rediffmail.com
}

Received 18 December 2010; Accepted 28 February 2011

\begin{abstract}
A rapid and simple high performance liquid chromatography method was developed and validated at $\lambda=275 \mathrm{~nm}$ for simultaneous determination of methocarbamol, paracetamol and diclofenac sodium (lamotrigine as an internal standard) from pharmaceutical preparation. The separation was performed using methanol: water: GAA, in the ratio of 400:600:05 (v/v) as the mobile phase. The detector response was linear in the range of 5 to $45 \mu \mathrm{g}, 3.25$ to $29.25 \mu \mathrm{g}$, 0.5 to $4.5 \mu \mathrm{g}$ for methocarbamol, paracetamol and diclofenac sodium respectively. The percentage assay of methocarbamol, paracetamol and diclofenac sodium was found between 100, 99.76 and $99.31 \%$ respectively. The described method has the advantage of being rapid and easy hence it can be applied for routine quality control analysis.
\end{abstract}

Keywords: Methocarbamol, Paracetamol, Diclofenac sodium, RP-HPLC, Pharmaceutical formulation

\section{Introduction}

Methocarbamol ${ }^{1,2}$ has the molecular formula $\mathrm{C}_{11} \mathrm{H}_{15} \mathrm{NO}_{5}$ and molecular weight $241.241 \mathrm{~g} / \mathrm{mol}$. Its chemical name is [2-hydroxy-3-(2-methoxyphenoxy)-propyl] aminoformate. Paracetamol ${ }^{2-4}$ has the molecular formula $\mathrm{C}_{8} \mathrm{H}_{9} \mathrm{NO}_{2}$ and a molecular weight $151.17 \mathrm{~g} / \mathrm{mol}$. Chemical name of paracetamol is $N$-[4-hydroxyphenyl]ethanamide. Diclofenac sodium ${ }^{2,4,5}$ has molecular formula $\mathrm{C}_{14} \mathrm{H}_{11} \mathrm{Cl}_{2} \mathrm{NO}_{2}$ and molecular weight $318.14 \mathrm{~g} / \mathrm{mol}$. Its chemical name is 2-[-2-(2, 6-dichlorophenyl) amino phenyl] ethanoic acid.

Methocarbamol $500 \mathrm{mg}$, paracetamol $325 \mathrm{mg}$ and diclofenac sodium $50 \mathrm{mg}$ in combination are available in market by brand name Robinaxol-D which is a muscle relaxant ${ }^{2}$. It causes skeletal muscle relaxation by preferential block of polysynaptic spinal refluxes ${ }^{2}$.

A literature survey reveals that there is no method reported so far for the simultaneous determination of these drugs in combined dosage form or any such pharmaceutical preparation 
by RP-HPLC using UV/Visible detector even though the validation of individual drug and in combination with other drugs are reported ${ }^{6-9}$. In this communication we report a new method for simultaneous determination of methocarbamol, paracetamol and diclofenac sodium in combination tablet.<smiles>COc1ccccc1OCC(O)COC(N)=O</smiles>

Methocarbamol<smiles>CC(=O)Nc1ccc(O)cc1</smiles>

Paracetamol<smiles>O=C(Cc1ccccc1Nc1c(Cl)cccc1Cl)O[Na]</smiles>

Diclofenac sodium

Figure 1. Structure of methocarbamol, paracetamol and diclofenac sodium

\section{Experimental}

The methocarbamol, paracetamol and diclofenac sodium and lamotrigine working standards were obtained as a gift sample from Watson Pharmaceutical Ltd. Cipla Ltd and Khandelwal Ltd, India with purity of $98.99,99.89$ and $99.99 \%$ respectively. The formulation of the tablet with combination of methocarbamol $500 \mathrm{mg}$, paracetamol $325 \mathrm{mg}$ and diclofenac sodium $50 \mathrm{mg}$ is available in market by brand name Robinaxol-D. All the reagents used were of chromatographic grade. All dilutions were performed in standard volumetric flask. Triple distilled water was prepared in the laboratory.

\section{Instrumentation and chromatographic conditions}

Chromatography was performed on Agelint high performance liquid chromatograph equipped with PU-1580 liquid chromatographic pump with $20 \mu \mathrm{L}$ loop and Agelint UV/Visible-1575 intelligent variable wavelength detector. The stationary phase is HiQ Sil $\mathrm{C}_{18} \mathrm{Hs}$ column $(4.6 \mathrm{~mm}$ ID $\times 250 \mathrm{~mm} \mathrm{~L}$ ), using (400: 600: 05) methanol: water: GAA as mobile phase. The chromatographic conditions had previously been optimized to achieve the best resolution and peak shape. Detection was performed at $\lambda=275 \mathrm{~nm}$ having flow rate of $1 \mathrm{~mL} / \mathrm{min}$. The typical chromatogram is shown in Figure 2.

\section{Stock solution of methocarbamol (Solution 1)}

$50 \mathrm{mg}$ of methocarbamol was accurately weighed, transferred into $1000 \mathrm{~cm}^{3}$ of volumetric flask and dissolved in the minimum amount of mobile phase and diluted up to the mark with mobile phase.

\section{Stock solution of paracetamol (Solution 2)}

$32.5 \mathrm{mg}$ of Paracetamol was accurately weighed and transferred into $100 \mathrm{~cm}^{3}$ of volumetric flask. It was dissolved in the minimum amount of mobile phase and then diluted up to the mark with mobile phase.

\section{Stock solution of diclofenac sodium (Solution 3)}

$5 \mathrm{mg}$ of Diclofenac sodium was accurately weighed, transferred into $100 \mathrm{~cm}^{3}$ of volumetric flask and dissolved in the minimum amount of mobile phase and then diluted up to the mark with mobile phase.

\section{Stock solution of lamotrigine (Solution 4)}

$10 \mathrm{mg}$ of Lamotrigine was accurately weighed, transferred into $100 \mathrm{~cm}^{3}$ of volumetric flask and was dissolved in the minimum amount of mobile phase and then diluted up to the mark 
with mobile phase .From this solution $1 \mathrm{~cm}^{3}$ of solution was used for each standard solution as an internal standard.

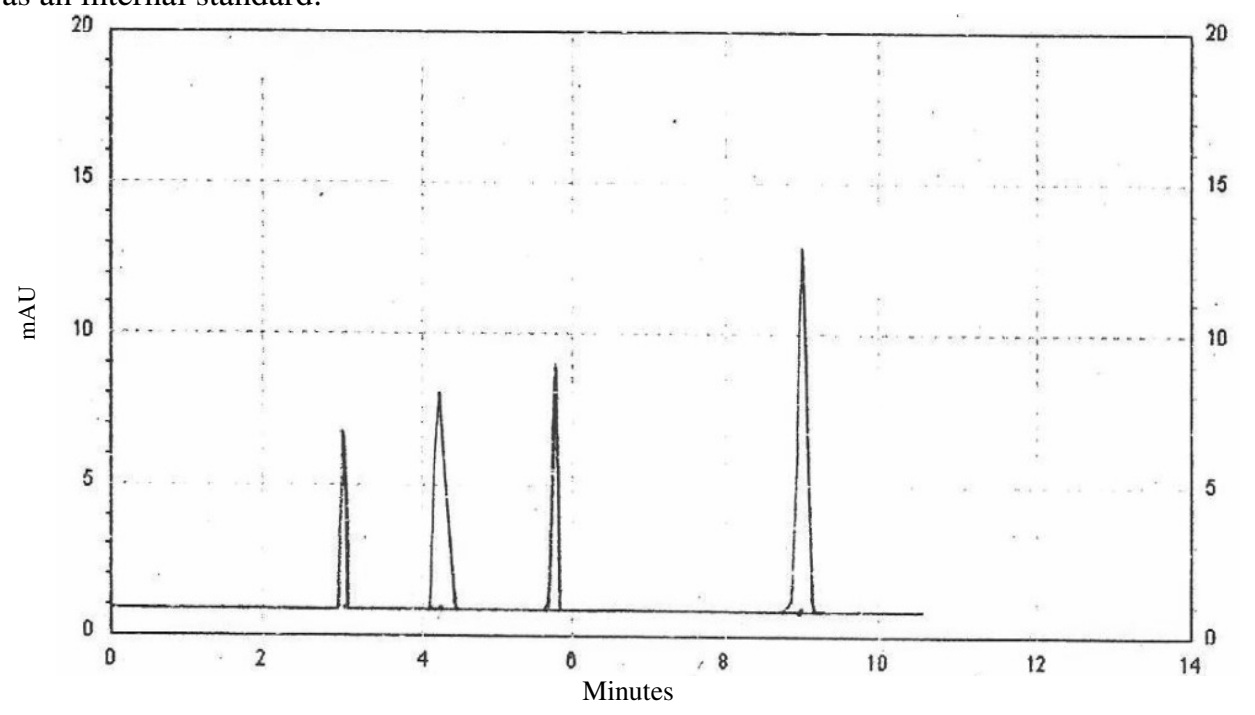

Figure 2. Chromatogram showing separation by RP-HPLC

(1) Diclofenac sodium, (2) Paracetamol, (3) Lamotrigine and (4) Methocarbamol

\section{Preparation of working standard solution}

A varying amount of stock solutions of methocarbamol, paracetamol and diclofenac sodium were added to a series of $50 \mathrm{~cm}^{3}$ volumetric flasks. To each flask $1 \mathrm{~cm}^{3}$ of internal standard (Solution 4) was added. These mixtures were then diluted up to the mark with mobile phase which gave concentration range between 5 to $45 \mu \mathrm{g} / \mathrm{cm}^{3}$ of methocarbamol, 3.25 to $29.25 \mu \mathrm{g} / \mathrm{cm}^{3}$ of paracetamol and 0.5 to $4.50 \mu \mathrm{g} / \mathrm{cm}^{3}$ of diclofenac sodium.

Preparation of sample solution (Solution 5)

Twenty tablets were weighed accurately and average weight of one tablet was calculated. The tablets were crushed to furnish a homogeneous powder and a quantity equivalent to one tablet $(1214 \mathrm{mg})$ was weighed and dissolved in a minimum quantity of methanol. This was transferred to the $1000 \mathrm{~cm}^{3}$ of standard volumetric flask with filtration by using a Whatman filter paper 41 . The filter paper was washed with methanol and the washings were collected in to the standard volumetric flask. The contents of the flask were then diluted up to the mark with methanol and used as a sample solution.

\section{Validation procedure}

\section{Linearity}

Different concentrations of methocarbamol (5 to $45 \mu \mathrm{g}$ ), paracetamol (3.25 to $29.25 \mu \mathrm{g}$ ) and diclofenac sodium $(0.5$ to $4.5 \mu \mathrm{g}$ ) were prepared from stock solution of respective API in mobile phase. $20 \mu \mathrm{L}$ of each solution was injected and the detector response for the different concentration was measured. The drug peak area was calculated for each concentration level and a graph was plotted of drug concentration against the peak area. The plot was linear in the range mentioned above. This experiment was performed thrice and the mean peak area response was used for calculations. The data was analyzed by linear regression least square fitting. The statistical data obtained is given in Table 1. 
Table 1. Linear regression data

\begin{tabular}{cccc}
\hline Regression Output & Methocarbamol & Paracetamol & Diclofenac sodium \\
\hline Constant & -0.07128 & -0.03356 & 0.13624 \\
Standard error of Y estimate & 1929.7277 & 1292.9234 & 1.86684 \\
R squared & 1 & 1 & 0.999 \\
No. of observations & 9 & 9 & 9 \\
Degree of freedom & 7 & 7 & 7 \\
X Coefficient $(\mathrm{S})(\mathrm{m})$ & 1.69585 & 2.7274 & 0.18114 \\
Standard error of coefficient & 0 & 0 & $3.33 \times 10^{-4}$ \\
\hline
\end{tabular}

\section{System suitability}

The coefficient of variation for peak area and retention time value for all the drugs was less than $2.00 \%$ for three replicate measurements of the same sample.

\section{Robustness of the method}

In the present work effect of flow rate was studied for the robustness of the method. The analysis was performed by using flow rate of $\pm 0.2 \mathrm{~cm}^{3} /$ minute. The results are summarized in Table 2, 3 and 4 which shows that method is not affected by deliberate change in the flow rate.

Table 2. Effect of flow rate - methocarbamol

\begin{tabular}{cccc}
\hline Flow rate, $\mathrm{cm}^{3} / \mathrm{min}$ & Retention time, min. & Theoretical plate & Resolution \\
\hline 1.00 & 9.05 & 8190.26 & 10.9333 \\
0.8 & 9.28 & 8618.03 & 10.96 \\
1.2 & 8.79 & 7732.27 & 10.71 \\
\hline
\end{tabular}

Table 3. Effect of flow rate - paracetamol

\begin{tabular}{cccc}
\hline Flow rate, $\mathrm{cm}^{3} / \mathrm{min}$ & Retention time, min. & Theoretical plate & Resolution \\
\hline 1.00 & 4.17 & 1111.12 & 4.5809 \\
0.8 & 4.41 & 1244.68 & 4.4833 \\
1.2 & 3.97 & 1007.01 & 4.6095 \\
\hline
\end{tabular}

Table 4. Effect of flow rate - (diclofenac sodium)

\begin{tabular}{cccc}
\hline Flow rate, $\mathrm{cm}^{3} / \mathrm{min}$ & Retention time, min. & Theoretical plate & Resolution \\
\hline 1.00 & 3.02 & 3656.28 & 13.7 \\
0.8 & 3.24 & 4199.04 & 13.7 \\
1.2 & 2.83 & 3196.05 & 13.76 \\
\hline
\end{tabular}

\section{Peak asymmetry and peak tailing}

The result shows that within the concentration ranges mentioned above there was an excellent correlation between peak area ratio and concentration of the each drug. The results are given in Table 5.

Table 5. Asymmetry factor and peak tailing factor

\begin{tabular}{ccc}
\hline Components & Asymmetry factor & Peak tailing factor \\
\hline Methocarbamol & 1 & 1 \\
Paracetamol & 0.5 & 0.75 \\
Diclofenac Sodium & 1 & 1 \\
Lamotrigine & 1 & 1 \\
\hline
\end{tabular}




\section{Assay (from pharmaceutical preparation)}

$20 \mu \mathrm{L}$ of working standard solution of methocarbamol, paracetamol and diclofenac sodium and sample solution were injected and chromatograms were developed and evaluated. The procedure was repeated three times, individually weighing the tablet powder (average weight of one tablet) each time. The responses from the standard and sample were used to calculate the amounts of the drug in the tablet. Results obtained are shown in Table 6.

Table 6. Results of HPLC assay studies $(n=3)$

\begin{tabular}{cccccccc}
\hline & $\begin{array}{c}\text { Weight of } \\
\text { sample } \\
\text { taken, mg }\end{array}$ & $\begin{array}{c}\text { Amount } \\
\text { found, mg }\end{array}$ & SD & C.O.V\% $\%$ Assay & SD & $\begin{array}{c}\text { C.O.V } \\
\%\end{array}$ \\
\hline Methocarbamol & 1213 & 500.53 & 0.2078 & 0.0415 & 100.1 & 0.0406 & 0.0405 \\
Paracetamol & 1212 & 323.42 & 1.5242 & 0.4712 & 99.51 & 0.5411 & 0.5437 \\
Diclofenac Na & 1211 & 49.75 & 0.4436 & 0.9816 & 99.51 & 0.5100 & 0.5125 \\
\hline
\end{tabular}

\section{Recovery}

The accuracy of the experiment was established by using a fixed amount of pre-analyzed sample i.e. $2.5 \mathrm{~cm}^{3}$ of solution 5 was taken in an $50 \mathrm{~cm}^{3}$ of standard volumetric flask to this $1 \mathrm{~cm}^{3}$ internal standard lamotrigine (solution 4) was added and the contents of the flask were diluted up to the mark with mobile phase. This served as the zero level i.e. 100\%. The results of recovery analysis are given in Table 7 . The mean recovery is within acceptable limits which indicate that the method is accurate.

Table 7. Results for recovery analysis $(n=3)$

\begin{tabular}{cccccc}
\hline S.No & Formulation & $\begin{array}{c}\text { Labeled } \\
\text { amount } \\
\text { (mg/tablet) }\end{array}$ & $\begin{array}{c}\text { Amount of } \\
\text { standard added } \\
\text { mg/Tab }\end{array}$ & $\begin{array}{c}\text { Amount } \\
\text { found } \\
\text { (mg/tablet) }\end{array}$ & $\begin{array}{c}\text { Percentage } \\
\text { recovery }\end{array}$ \\
\hline 1 & Methocarbamol & 500 & 1.25 & 1.25 & 100 \\
2 & Paracetamol & 325 & 0.814 & 0.814 & 100 \\
3 & Diclofenac Na & 50 & 0.122 & 0.122 & 100 \\
\hline
\end{tabular}

Each reading is the mean of the three readings

\section{Determination of reliability of the assay method}

Statistical parameters namely standard deviation (S.D) and percentage coefficient of variation (C.O.V. \%) were calculated to study the reliability of the method. Low values of these statistical parameters for recovery indicates high reliability of the method, these values are given in Table 8 .

Table 8. Statistical parameters

\begin{tabular}{ccccc}
\hline & Level & Amount found mg/tablet & Standard deviation & C.O.V.\% \\
\hline Methocarbamol & 0.0 & 1.25 & 0.00 & 0.00 \\
Paracetamol & 0.0 & 0.814 & 0.0003 & 0.0368 \\
Diclofenac Na & 0.0 & 0.122 & 0.00 & 0.00 \\
\hline
\end{tabular}

\section{Results and Discussion}

Use of methanol: water: GAA in volume ratio of 400: 600: 05 resulted in good separation of the drugs with no interfering peak at the retention time of the methocarbamol, paracetamol and diclofenac sodium and lamotrigine viz. 9.00 minute, 4.15 minute, 3.00 minute and 5.75 minute respectively as shown in Figure 2.

Figure 2 shows typical chromatogram obtained from methocarbamol, paracetamol and diclofenac sodium. Regression analysis for the calibration data for all the drugs showed that 
the dependent variable (peak area) and independent variable (concentration) were represented by the equation $\mathrm{y}=1.69585 \mathrm{x}+0.07128$ for methocarbamol, $\mathrm{y}=0.36401 \mathrm{x}-$ 38.37153 for paracetamol, $\mathrm{y}=0.18114 \mathrm{x}+0.13624$ for diclofenac sodium.

The correlation coefficient obtained was 1.00, 1.00 and 0.999 for methocarbamol, paracetamol and diclofenac sodium respectively. It shows the good linear relationship between the concentration range 5 to $45 \mu \mathrm{g}, 3.25$ to $29.25 \mu \mathrm{g}$ and 0.5 to $4.5 \mu \mathrm{g}$ for methocarbamol, paracetamol and diclofenac sodium respectively.

The coefficient of variation for peak area and retention time value for all the drugs was less than $2 \%$ for three replicate measurements of the same sample. This showed that the method and the system are suitable for determination of methocarbamol, paracetamol and diclofenac sodium.

The assay of methocarbamol, paracetamol and diclofenac sodium was found to be $100.10,99.51$ and $99.51 \%$ respectively. The recovery of methocarbamol, paracetamol, and diclofenac sodium was found to be 100,100 and $100 \%$ respectively from recovery studies which indicates high accuracy of the method.

\section{Conclusion}

As the proposed method is highly accurate, selective and precise hence can be used for a routine quality control analysis and quantitative simultaneous determination of methocarbamol, paracetamol and diclofenac sodium in pharmaceutical preparations. The method is also fast and requires approximately 10 minute for analysis.

\section{References}

1. United State Pharmacopoeia 2005, $28^{\text {th }}$ Edn.

2. Indian Drug Review September-October 2005.

3. British Pharmacopoeia 2007, Vol I.

4. Indian Pharmacopoeia 1996, Vol II.

5. United State Pharmacopoeia, 1995 Published by USP Conventions Inc., U.S.A.

6. Chawla J L, Sodhi R A and Sane R T, Indian Drug, 1996, 33(4), 280-285

7. Nikolin B, Imamovic B, Medanhodzic-Vuk S and Sober M, J Basic Med Sci., 2004, 4(2), 5-9.

8. Metherall R and Ford D, Ther Drug Monit., 1988, 10, 101.

9. Plavsic F and Culig J, Human Toxicol., 1985, 4(3), 317-332.

10. United States Pharmacopoeia (USP 24), Asian Edition, Published by United States Pharmacopeial Convention, Inc., USA, 2000

11. Stenhoff H, Lagerstrom P O and Andersen C, J Chromatogr B Biomed Appl., 1999, 731(2), 411-417. 


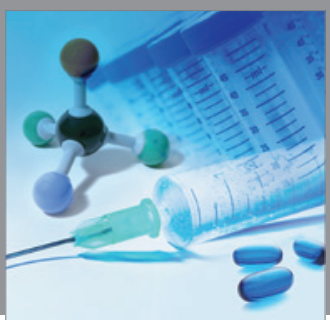

International Journal of

Medicinal Chemistry

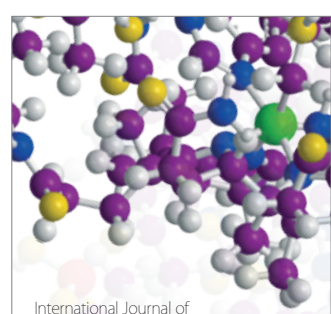

Carbohydrate Chemistry

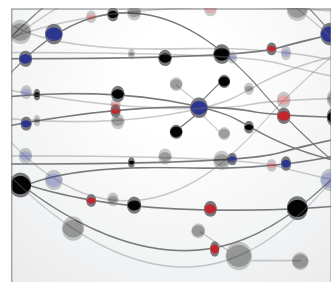

The Scientific World Journal
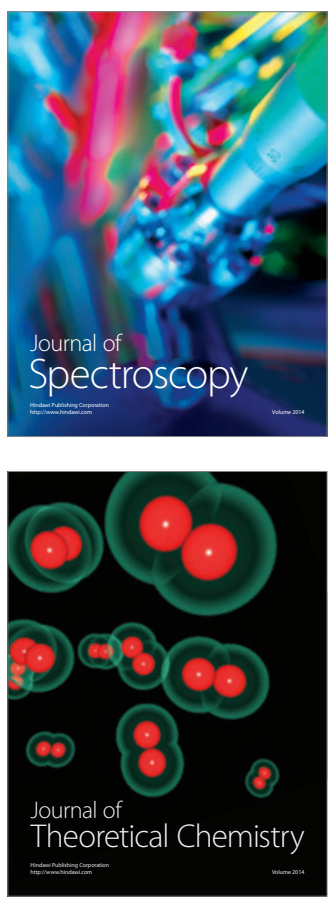
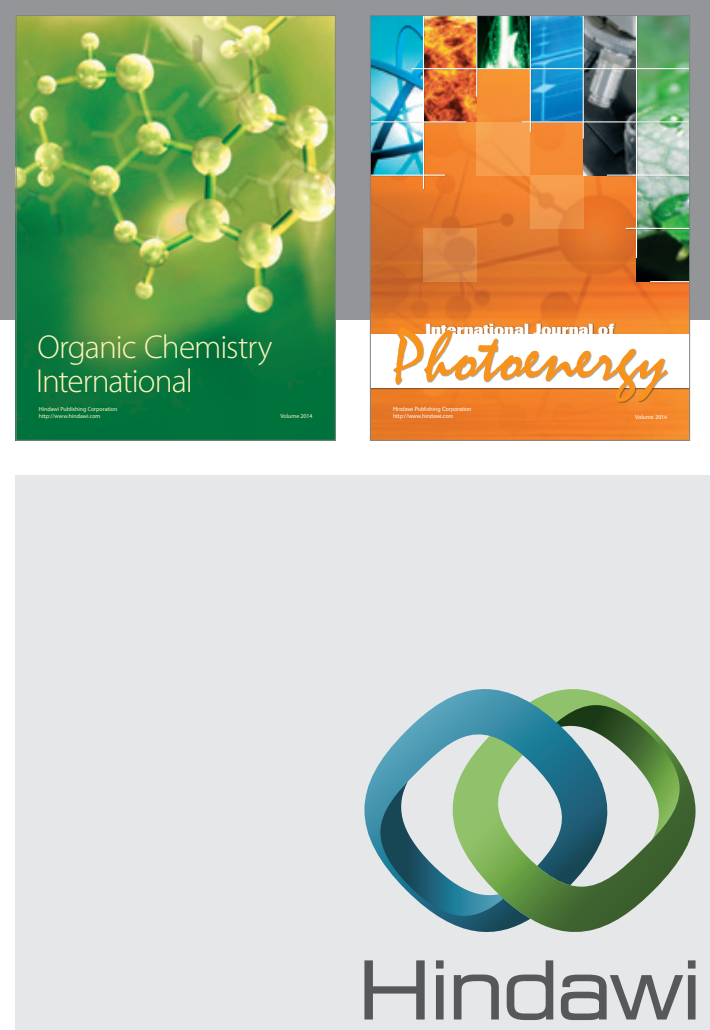

Submit your manuscripts at

http://www.hindawi.com
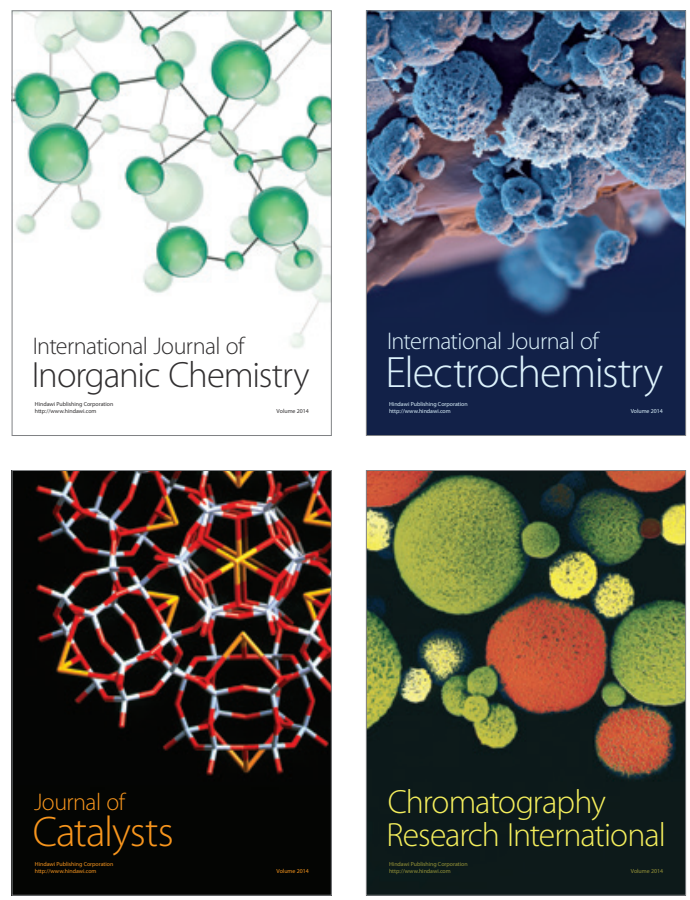
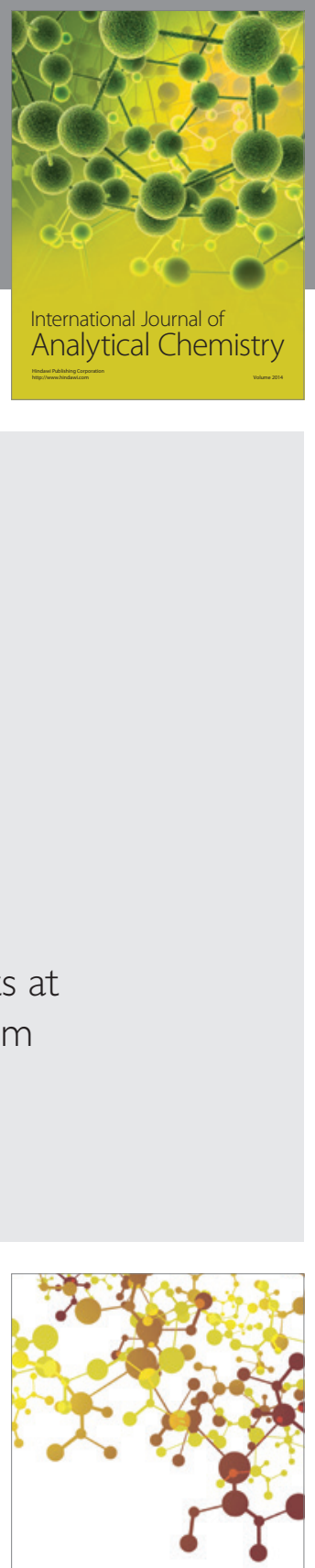

Journal of

Applied Chemistry
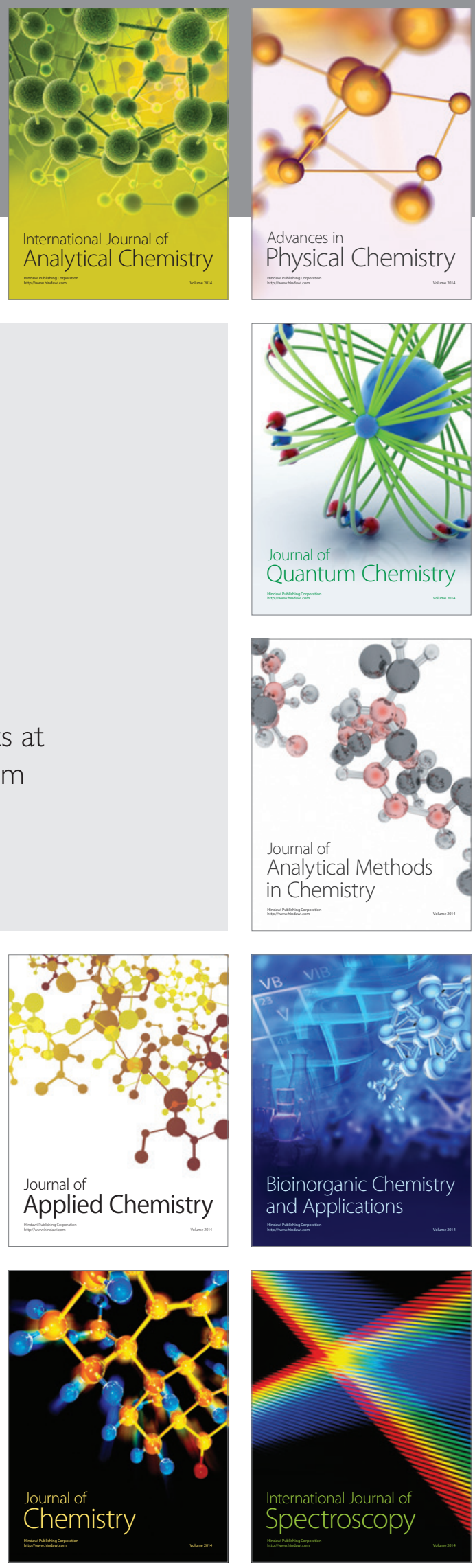